\title{
Dual-defect-modified graphitic carbon nitride with boosted photocatalytic activity under visible light
}

\author{
Hideyuki Katsumata ${ }^{1 \star}$, Fumiya Higashi ${ }^{1}$, Yuya Kobayashi ${ }^{1}$, Ikki Tateishi ${ }^{2}$, Mai Furukawa ${ }^{1}$ \& \\ Satoshi Kaneco ${ }^{1,2}$
}

The development of photocatalysts that efficiently degrade organic pollutants is an important environmental-remediation objective. To that end, we report a strategy for the ready fabrication of oxygen-doped graphitic carbon nitride (CN) with engendered nitrogen deficiencies. The addition of $\mathrm{KOH}$ and oxalic acid during the thermal condensation of urea led to a material that exhibits a significantly higher pseudo-first-order rate constant for the degradation of bisphenol A (BPA) $\left(0.0225 \mathrm{~min}^{-1}\right)$ compared to that of $\mathrm{CN}\left(0.00222 \mathrm{~min}^{-1}\right)$. The enhanced photocatalytic activity for the degradation of BPA exhibited by the dual-defect-modified CN (Bt-OA-CN) is ascribable to a considerable red-shift in its light absorption compared to that of $\mathrm{CN}$, as well as its modulated energy band structure and more-efficient charge separation. Furthermore, we confirmed that the in-situ-formed cyano groups in the Bt-OA-CN photocatalyst act as strong electron-withdrawing groups that efficiently separate and transfer photo-generated charge carriers to the surface of the photocatalyst. This study provides novel insight into the in-situ dual-defect strategy for $\mathrm{g}-\mathrm{C}_{3} \mathrm{~N}_{4}$, which is extendable to the modification of other photocatalysts; it also introduces $\mathrm{Bt}-\mathrm{OA}-\mathrm{CN}$ as a potential highly efficient visible-light-responsive photocatalyst for use in environmental-remediation applications.

Photocatalytic semiconductor technology is considered to be useful and promising for the remediation of environmental organic contaminants, because it can effectively decompose pollutants into inorganic compounds, such as $\mathrm{CO}_{2}$ and $\mathrm{H}_{2} \mathrm{O}$. Therefore, discovering highly active photocatalysts continues to be a worldwide effort. Recently, graphitic carbon nitride $\left(\mathrm{g}-\mathrm{C}_{3} \mathrm{~N}_{4}\right)$, which is a $\pi$-conjugated polymer semiconductor, has captured the attentions of catalysis researchers, due to its unique characteristics that include its high chemical and thermal stabilities, preferable electronic band alignment, lack of toxicity, cost effectiveness, ease of preparation, and visible-light responsiveness ${ }^{1-8}$. It has also stimulated numerous studies on $\mathrm{H}_{2}$ evolution through water splitting ${ }^{1,4,9-11}$, organic-pollutant degradation ${ }^{12,13}$, artificial photosynthesis ${ }^{6,14,15}$, and $\mathrm{CO}_{2}$ reduction ${ }^{16,17}$. However, g- $\mathrm{C}_{3} \mathrm{~N}_{4}$ exhibits poor photocatalytic performance because of its limited ability to absorb visible light, its high rate of hole-electron pair recombination, low specific surface area, and few reactive sites ${ }^{18-20}$. Many strategies have been used in attempts to solve the above-mentioned disadvantages and to improve the photocatalytic activity of g- $\mathrm{C}_{3} \mathrm{~N}_{4}$, including morphological modifications ${ }^{21-25}$, elemental doping ${ }^{26-31}$, modifications with non-metallic and metallic materials ${ }^{32-35}$, surface chemical modifications ${ }^{10,36-38}$, and combinations with other photocatalysts to fabricate hybrid composites ${ }^{12,16,19,39-46}$.

The formation of nitrogen defects in the $\mathrm{g}-\mathrm{C}_{3} \mathrm{~N}_{4}$ framework is an effective way of reducing the charge-transfer barrier and improving its photocatalytic performance under visible light ${ }^{46}$. As a result, the defect-control methodology has been intensively studied with the aim of increasing the visible-light absorption of $g-\mathrm{C}_{3} \mathrm{~N}_{4}$ and engender it with superior activity ${ }^{46-50}$. Defects are easily introduced into $g-\mathrm{C}_{3} \mathrm{~N}_{4}$ by modifying its synthesis conditions, which is ascribable to its metal-free polymer properties and heterogeneous atomic environment; i.e., the various bonding states of its two- and three-coordinated nitrogen atoms. In particular, the formation of nitrogen defects has recently been demonstrated to significantly enhance the photocatalytic activity of $g-\mathrm{C}_{3} \mathrm{~N}_{4}$ under visible light ${ }^{47}$.

${ }^{1}$ Department of Chemistry for Materials, Graduate School of Engineering, Mie University, Tsu, Mie, 514-8507, Japan. ${ }^{2}$ Mie Global Environment Center for Education \& Research, Mie University, Tsu, Mie, 514-8507, Japan. *email: hidek@chem.mie-u.ac.jp 

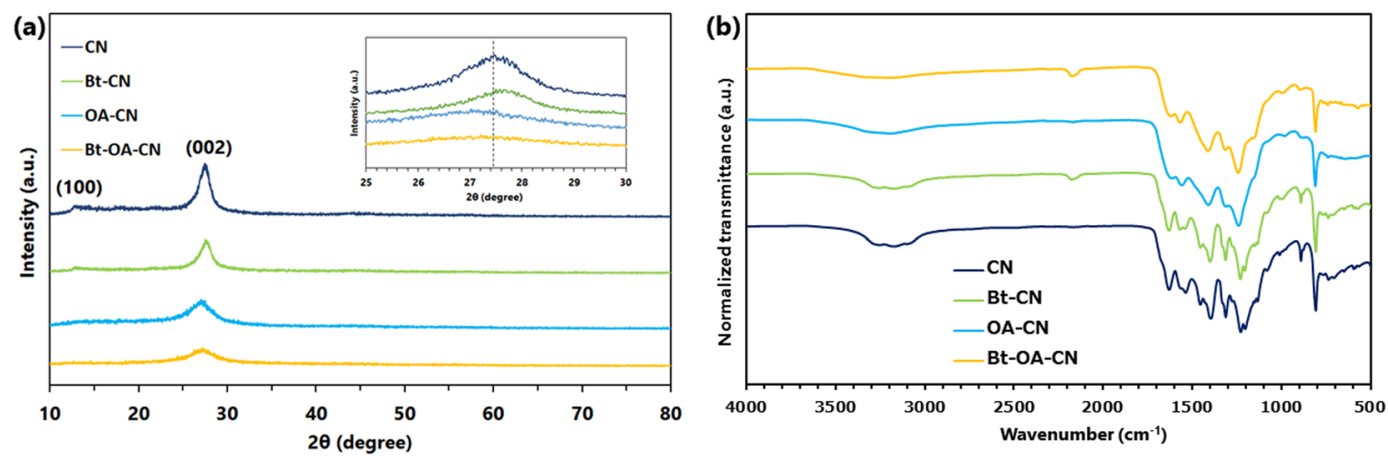

Figure 1. (a) XRD patterns and (b) FTIR spectra of $\mathrm{CN}, \mathrm{Bt}-\mathrm{CN}, \mathrm{OA}-\mathrm{CN}$, and Bt-OA-CN.

Nitrogen defects in g- $\mathrm{C}_{3} \mathrm{~N}_{4}$ can create mid-gap bands, serve as reactive sites for the excitation of charge carriers, and expand the optical responses of photocatalyst materials. Furthermore, nitrogen defects supply trapping sites for photo-induced charge carriers, preventing their recombination and promoting the overall quantum efficiency ${ }^{51-53}$. Many strategies for generating nitrogen defects in $\mathrm{g}-\mathrm{C}_{3} \mathrm{~N}_{4}$ have been investigated to date, including polymerization-temperature control ${ }^{47,53}$, hydrothermal treatment ${ }^{51}$, and hydrogen reduction ${ }^{46,52}$. KOH treatment of urea, as a precursor of $\mathrm{g}-\mathrm{C}_{3} \mathrm{~N}_{4}$, promotes alkali-assisted thermal condensation and is also an effective method for producing nitrogen defects. This method was used to demonstrate that the band alignment of g- $\mathrm{C}_{3} \mathrm{~N}_{4}$ can be controlled by the formation of cyano groups and surface nitrogen deficiencies in the $\mathrm{g}_{-} \mathrm{C}_{3} \mathrm{~N}_{4}$ framework, which are preferable for collecting incident visible light and effectively separating photo-generated hole-electron pairs ${ }^{54}$.

On the other hand, non-metal doping $(\mathrm{B}, \mathrm{C}, \mathrm{O}, \mathrm{F}, \mathrm{P}$, and $\mathrm{S})$ has been reported to play a significant role in enhancing solar-light absorption by $g-\mathrm{C}_{3} \mathrm{~N}_{4}$ and its photocatalytic activity ${ }^{55}$. In particular, $\mathrm{O}$-doping accelerates the photocatalytic performance of $\mathrm{g}-\mathrm{C}_{3} \mathrm{~N}_{4}$ due to improvements in its electronic band structure and charge-carrier usage ${ }^{56-58}$. In addition, $\mathrm{O}$-doped $\mathrm{g}-\mathrm{C}_{3} \mathrm{~N}_{4}$ is relatively easy to fabricate by treating melamine (as a precursor) with $\mathrm{H}_{2} \mathrm{O}_{2}$, or by treating $\mathrm{g}-\mathrm{C}_{3} \mathrm{~N}_{4}$ with $\mathrm{H}_{2} \mathrm{O}_{2}$ under an oxygen atmosphere ${ }^{59-61}$. Other $\mathrm{O}$-doping methods that use thermal oxidation ${ }^{62}$ and hydrothermal treatment have also been established ${ }^{63-65}$. Recently, Qiu et al. ${ }^{66}$ developed a simple, low-cost and green method for the synthesis of $\mathrm{O}$-doped porous $\mathrm{g}_{-} \mathrm{C}_{3} \mathrm{~N}_{4}$ by condensing oxalic acid with urea; this material displayed a significantly enhanced ability to efficiently degrade contaminants due to its high specific surface area, efficient charge separation, and its intense visible-light-absorption properties $(\approx 700 \mathrm{~nm})$. However, to the best of our knowledge, there are very few reports on dual modifications involving oxygen doping and nitrogen defects in a $\mathrm{g}-\mathrm{C}_{3} \mathrm{~N}_{4}$ framework ${ }^{67,68}$.

In this work, we introduce a facile method for the synthesis of dual-modified O-doped g- $\mathrm{C}_{3} \mathrm{~N}_{4}$ containing nitrogen defects through the thermal polymerization of urea treated with $\mathrm{KOH}$ and oxalic acid. The dual-defect-modified g- $\mathrm{C}_{3} \mathrm{~N}_{4}$ (Bt-OA-CN) exhibits an intense red-shift in light absorption as well as a modulated energy band structure and more-effective separation of charge carriers compared to g- $\mathrm{C}_{3} \mathrm{~N}_{4}$. Because of its improved visible-light absorption and efficient charge separation, the Bt-OA-CN photocatalyst exhibits higher photocatalytic activity for the degradation of bisphenol A (BPA) compared to pristine g- $\mathrm{C}_{3} \mathrm{~N}_{4}(\mathrm{CN}), \mathrm{N}$-defect CN $(\mathrm{Bt}-\mathrm{CN})$, and $\mathrm{O}$-doped $\mathrm{CN}(\mathrm{OA}-\mathrm{CN})$ when irradiated with visible light. The excellent photocatalytic performance of Bt-OA-CN is ascribable to synergism between the oxygen dopants and the nitrogen defects, as well as the introduction of cyano moieties, which serve as strong electron-withdrawing groups that efficiently separate and transfer photo-induced charge carriers to the surface of the photocatalyst.

\section{Results and Discussion}

Characterizing the photocatalysts. As shown in Fig. 1, all samples exhibit very similar powder X-ray diffraction (XRD) patterns and Fourier-transform infrared (FTIR) spectra, indicating that the treated samples (Bt-, $\mathrm{OA}-$ and Bt-OA-CNs) retain the general $\mathrm{CN}$ structure. The XRD pattern of $\mathrm{CN}$ exhibits two characteristic peaks at $13.0^{\circ}$ and $27.5^{\circ}$, assigned to the (100) and (002) planes, which correspond to in-plane packing and the characteristic interlayer stacking of aromatic systems, respectively ${ }^{69}$. Fig. 1a clearly shows that the (002) peak shifts to higher angle in $\mathrm{Bt}-\mathrm{CN}$, but to lower angles in $\mathrm{OA}-$ and $\mathrm{Bt}-\mathrm{OA}-\mathrm{CNs}$ compared to $\mathrm{CN}$, suggesting a decrease and increases in interlayer distance in Bt-CN, and OA- and Bt-OA-CNs, respectively ${ }^{70}$. In addition, both peaks in the spectra of the treated samples were broader and weaker than those in the spectrum of $\mathrm{CN}$, which is ascribable to decreases in the ordered structure within the $\mathrm{g}-\mathrm{C}_{3} \mathrm{~N}_{4}$ framework.

The normalized FTIR spectrum of CN (Fig. 1b) exhibits multiple peaks in the $1200-1600 \mathrm{~cm}^{-1}$ range that are attributable to the typical C-N stretching modes of C-N heterocycles ${ }^{71}$. The sharp peak at $810 \mathrm{~cm}^{-1}$ and the broad ones in the $3000-3400 \mathrm{~cm}^{-1}$ range are due to the breathing mode of the heptazine units and $\mathrm{N}-\mathrm{H}$ stretching modes, respectively ${ }^{72}$. The spectra of the samples prepared with $\mathrm{KOH}(\mathrm{Bt}-\mathrm{CN}$ and Bt-OA-CN) exhibit additional peaks at $2177 \mathrm{~cm}^{-1}$ that correspond to the asymmetric stretching mode of the cyano group ${ }^{54}$. Clearly, the addition of $\mathrm{KOH}$ during the preparation of $\mathrm{g}-\mathrm{C}_{3} \mathrm{~N}_{4}$ promotes the formation of cyano groups in its framework. On the other hand, the peaks at $1238 \mathrm{~cm}^{-1}$, which corresponds to the $\mathrm{C}-\mathrm{N}$ stretching vibration, were clearly broader in the spectra of the oxalic-acid-added samples (OA-CN and Bt-OA-CN), which indicates that some of the C-N bonds were replaced with $\mathrm{C}-\mathrm{O}$ bonds ${ }^{66}$. Furthermore, markedly lower normalized intensities of the broad peaks between 

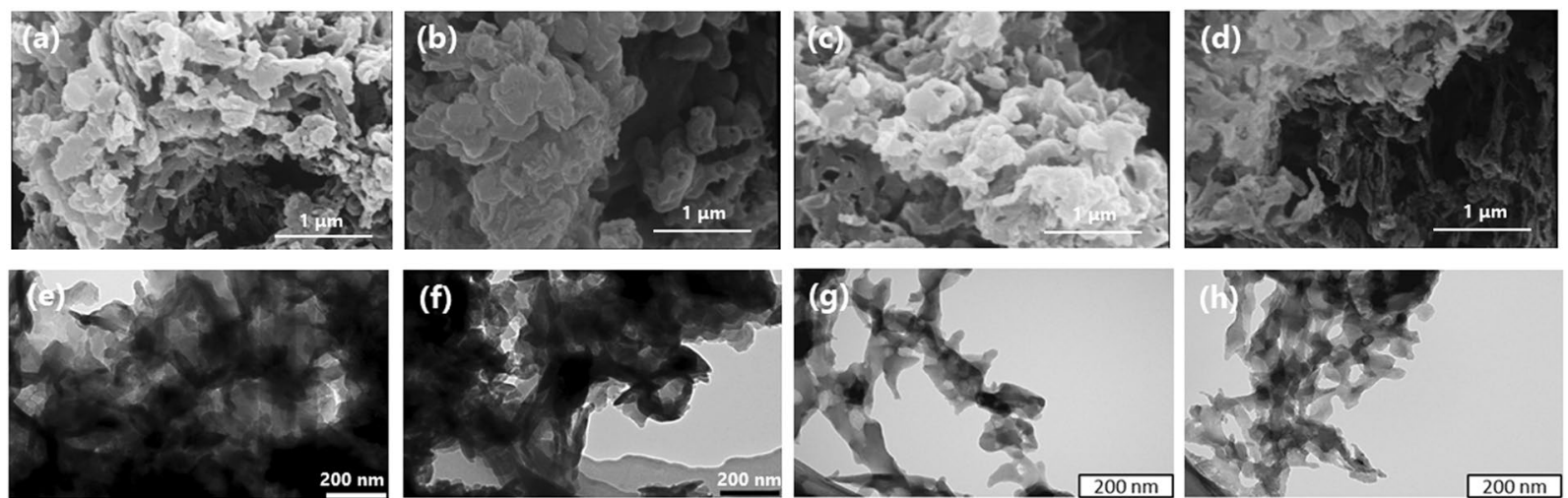

Figure 2. (a-d) SEM and (e-h) TEM images of (a,e) CN, (b,f) Bt-CN, (c,g) OA-CN, and (d,h) Bt-OA-CN.

(a)

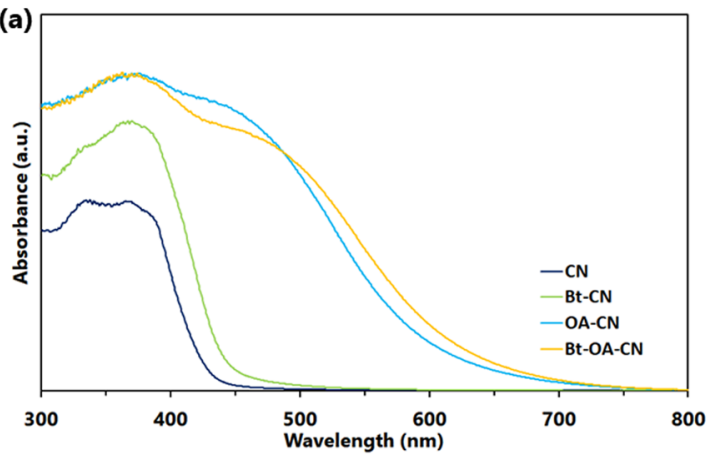

(b)

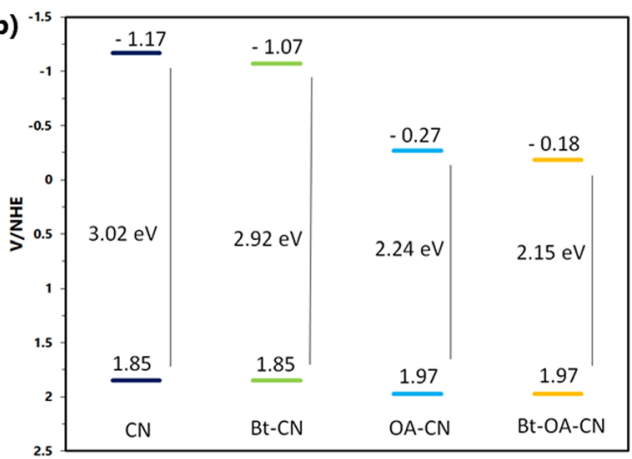

Figure 3. (a) UV-vis DRS spectra and (b) band structure alignments of $\mathrm{CN}, \mathrm{Bt}-\mathrm{CN}, \mathrm{OA}-\mathrm{CN}$ and Bt-OA-CN.

\begin{tabular}{|l|l|l|l|}
\hline Photocatalyst & $\begin{array}{l}\text { BET specific surface } \\
\text { area }\left(\mathbf{m}^{2} \mathbf{g}^{-1}\right)\end{array}$ & $\begin{array}{l}\text { Total pore volume } \\
\left(\mathbf{c m}^{\mathbf{3}} \mathbf{g}^{-1}\right)\end{array}$ & $\begin{array}{l}\text { Average pore } \\
\text { diameter }(\mathbf{n m})\end{array}$ \\
\hline CN & 54.6 & 0.39 & 28.5 \\
\hline Bt-CN & 34.7 & 0.22 & 25.9 \\
\hline OA-CN & 54.6 & 0.26 & 18.9 \\
\hline Bt-OA-CN & 32.4 & 0.22 & 26.7 \\
\hline
\end{tabular}

Table 1. BET specific surface areas, total pore volumes, and average pore diameters of $\mathrm{CN}, \mathrm{Bt}-\mathrm{CN}, \mathrm{OA}-\mathrm{CN}$, and Bt-OA-CN.

3000 and $3400 \mathrm{~cm}^{-1}$ were observed in the spectra of the OA-CN and Bt-OA-CN photocatalysts. These results indicate that the use of oxalic acid decreases the concentration of $\mathrm{N}-\mathrm{H}$ groups, suggestive of smaller planar layers.

The morphologies of $\mathrm{CN}, \mathrm{Bt}-\mathrm{CN}, \mathrm{OA}-\mathrm{CN}$, and Bt-OA-CN were observed by scanning electron microscopy (SEM) and transmission electron microscopy (TEM), the results of which are shown in Fig. 2. The SEM and TEM images reveal that all samples possess sheet-like structures. Therefore, the additions of $\mathrm{KOH}$ and oxalic acid preserved the characteristic sheet structure and thin layers of g- $\mathrm{C}_{3} \mathrm{~N}_{4}$. On the other hand, the OA-CN and Bt-OA-CN samples were fragmented, suggesting that oxalic acid reacts with urea as the precursor during thermal polymerization to cause fragmentation of the $\mathrm{g}_{-} \mathrm{C}_{3} \mathrm{~N}_{4}$ framework ${ }^{73}$. These results are in good agreement with the $\mathrm{XRD}$ and FTIR results. To further understand the specific surface areas and pore size distributions of these catalyst, the samples were subjected to $\mathrm{N}_{2}$ adsorption-desorption experiments. All samples exhibited typical type-IV isotherms with hysteresis loops, indicating the presence of mesopores (Fig. S1a). The Brunauer-Emmett-Teller (BET) specific surface areas of $\mathrm{CN}$ and OA-CN were both $54.6 \mathrm{~m}^{2} / \mathrm{g}$, whereas those of Bt-CN and Bt-OA-CN were smaller, at 34.7 and $32.4 \mathrm{~m}^{2} / \mathrm{g}$, respectively (Table 1). CN exhibits three peaks at about 3,30 , and $45 \mathrm{~nm}$ in its Barrett-Joyner-Halenda (BJH) pore size distribution profile, while the profiles of the treated catalysts were different (Fig. S1b). Therefore, we conclude that the addition of $\mathrm{KOH}$ modifies the BET surface area and BJH pore distribution of $\mathrm{CN}$, while the addition of oxalic acid only affects its $\mathrm{BJH}$ pore distribution.

The light absorption properties of the resultant samples were explored by UV-vis diffuse reflectance spectroscopy (DRS) (Fig. 3a). CN exhibits an intrinsic absorption edge at around $460 \mathrm{~nm}$, with a calculated band gap of $3.02 \mathrm{eV}$ as determined by the Kubelka-Munk method (Fig. S2a). The modified catalysts exhibit expanded absorption wavelength regions compared to that of CN. In particular, Bt-OA-CN is able to absorb above $740 \mathrm{~nm}$. The 


\begin{tabular}{|l|l|l|l|l|}
\hline \multirow{2}{*}{ Photocatalyst } & \multicolumn{3}{|l|}{ Atomic ratio (\%) } & \\
\cline { 2 - 5 } & C & N & O & N/C \\
\hline CN & 43.0 & 56.0 & 1.0 & 1.30 \\
\hline Bt-CN & 44.1 & 54.1 & 1.8 & 1.23 \\
\hline OA-CN & 43.0 & 54.3 & 2.8 & 1.26 \\
\hline Bt-OA-CN & 43.5 & 53.4 & 3.1 & 1.23 \\
\hline
\end{tabular}

Table 2. XPS-determined surface atomic ratios and N/Cs of $\mathrm{CN}, \mathrm{Bt}-\mathrm{CN}, \mathrm{OA}-\mathrm{CN}$, and Bt-OA-CN.

corresponding bandgaps of Bt-CN, OA-CN, and Bt-OA-CN were estimated to be 2.92, 2.24, and $2.15 \mathrm{eV}$, respectively. Therefore, the addition of $\mathrm{KOH}$ and oxalic acid during the thermal condensation of urea drastically modified the optical features and light-harvesting capability of $g-C_{3} \mathrm{~N}_{4}$. To explain the narrower bandgaps of the treated CNs, the samples were subjected to valence-band (VB) X-ray photoelectron spectroscopy (XPS) (Fig. S2b). The VB positions of both $\mathrm{CN}$ and Bt-CN were found to be similar (about $1.85 \mathrm{eV}$ ) whereas those of OA-CN and Bt-OA-CN are downshifted to $1.97 \mathrm{eV}$, which is ascribable to the higher $\mathrm{O} 2 \mathrm{p}$ orbital energy compared to that of the $\mathrm{N} 2 \mathrm{p}$ orbital through the introduction of $\mathrm{O}$ atoms (vide infra $)^{74}$. On the other hand, the $\mathrm{N}$-defects described below have little effect on the VB position of $g-\mathrm{C}_{3} \mathrm{~N}_{4}$. The DRS and VB-XPS results reveal that the narrower bandgaps of the modified samples originate from lower conduction-band (CB) energies, compared with that of g- $\mathrm{C}_{3} \mathrm{~N}_{4}$; the schematic band structures are shown in Fig. $3 \mathrm{~b}$.

In order to further understand the effects of adding $\mathrm{KOH}$ and oxalic acid on the surface chemical composition and elemental chemical state of $\mathrm{g}-\mathrm{C}_{3} \mathrm{~N}_{4}$, the samples were subjected to XPS. The atomic ratios in the $\mathrm{CN}, \mathrm{Bt}-\mathrm{CN}$, $\mathrm{OA}-\mathrm{CN}$, and Bt-OA-CN samples were determined from their XPS survey spectra (Fig. S3). The N/C atomic ratio of the $\mathrm{CN}$ sample was found to be 1.30 , which is very close to the theoretical value (Table 2). However, the XPS results showed a significantly lower N/C ratio (1.23) on the surface of $g-\mathrm{C}_{3} \mathrm{~N}_{4}$ prepared by the addition of $\mathrm{KOH}$ and oxalic acid, which suggests that surface $\mathrm{N}$ defects have been introduced. Furthermore, clear O1s peaks were found in the spectra of OA- and Bt-OA-CN, indicating that $\mathrm{N}$ atoms in the $\mathrm{g}_{-} \mathrm{C}_{3} \mathrm{~N}_{4}$ framework had been substituted with $\mathrm{O}$ atoms. To further confirm that the addition of $\mathrm{KOH}$ and oxalic acid introduces $\mathrm{O}$-dopants and $\mathrm{N}$-defects, high-resolution XPS spectra of $\mathrm{CN}, \mathrm{Bt}-\mathrm{CN}, \mathrm{OA}-\mathrm{CN}$ and Bt-OA-CN were acquired and divided into their chemical states (Fig. 4). The C1s XPS spectra of $\mathrm{CN}$ and Bt-CN are composed of two peaks at 284.7 and $288.0 \mathrm{eV}$ that correspond to graphitic carbon and $\mathrm{N}-\mathrm{C}=\mathrm{N}$ coordination, respectively (Fig. $4 \mathrm{a})^{75,76}$. We observed that the $\mathrm{C} 1 \mathrm{~s}$ spectra of OA- and Bt-OA-CN exhibit a new component located at $286.0 \mathrm{eV}$, which is attributed to $\mathrm{C}-\mathrm{O}$ bonding ${ }^{76}$. As seen in Table $\mathrm{S} 1$, the $\mathrm{N}-\mathrm{C}=\mathrm{N}$ ratios were remarkably lower, while the $\mathrm{C}-\mathrm{O}$ ratios were remarkably higher in the OA- and Bt-OA-CN samples, compared with those of $\mathrm{CN}$, reflecting the replacement of the $\mathrm{N}$ atoms in the $\mathrm{g}-\mathrm{C}_{3} \mathrm{~N}_{4}$ framework with $\mathrm{O}$ atoms in the OA- and Bt-OA-CN samples. Therefore, we conclude that the addition of oxalic acid during the thermal condensation of $\mathrm{g}-\mathrm{C}_{3} \mathrm{~N}_{4}$ leads to O-doping in the $\mathrm{g}-\mathrm{C}_{3} \mathrm{~N}_{4}$ framework. In addition, the $\mathrm{N} 1 \mathrm{~s}$ spectrum of $\mathrm{CN}$ was fitted by four peaks at $398.5,400.3,401.2$, and $404.0 \mathrm{eV}$ that correspond to triazine rings $(\mathrm{C}-\mathrm{N}=\mathrm{C})$, tertiary nitrogen $\left(\mathrm{N}-(\mathrm{C})_{3}\right)$, amino functions $(\mathrm{N}-\mathrm{H})$, and $\pi$-excitation, respectively ${ }^{75}$. The spectra of Bt- and Bt-OA-CN exhibit tertiary-nitrogen peaks that are located at slightly lower binding energies than that of $\mathrm{CN}$, which is ascribable to the formation of cyano groups (Table $\mathrm{S} 2$ and Fig. $4 \mathrm{~b})^{77}$. These results are in good accordance with the FTIR observations (Fig. 1b). Furthermore, the $\mathrm{C}-\mathrm{N}=\mathrm{C}$ ratios of Bt-, OA- and Bt-OA-CN were lower compared to that of $\mathrm{CN}$ (from 0.77 to 0.66 ), which provides strong evidence that $\mathrm{N}$-defects and $\mathrm{O}$-dopants were formed at the secondary nitrogen $(\mathrm{C}-\mathrm{N}=\mathrm{C})$ atoms of the $\mathrm{g}-\mathrm{C}_{3} \mathrm{~N}_{4}$-framework surface by the addition of $\mathrm{KOH}$ and oxalic acid during thermal polymerization. The O1s XPS spectra of CN and Bt-CN (Fig. 4c) each exhibit one component, at 532.6 and $531.6 \mathrm{eV}$, respectively, which are attributed to water and adsorbed $\mathrm{CO}_{2}{ }^{78}$. On the other hand, the O1s spectra of OA- and Bt-OA-CN exhibit peaks at $532.0 \mathrm{eV}$ that correspond to $\mathrm{C}-\mathrm{O}-\mathrm{C}$ species $^{78}$. The $\mathrm{O} 1 \mathrm{~s}$ spectra clearly support the introduction of $\mathrm{C}-\mathrm{O}$ bonds in the $\mathrm{g}_{-} \mathrm{C}_{3} \mathrm{~N}_{4}$ framework.

In addition to their effects on the bandgaps and the chemical structures, the $\mathrm{N}$-defects and $\mathrm{O}$-dopants in g- $\mathrm{C}_{3} \mathrm{~N}_{4}$ are also presumed to affect the photogenerated charge separation, which was examined by photoluminescence (PL) and time-resolved fluorescence-decay (TRPL) experiments. The PL spectra of CN and the modified CNs are shown in Fig. 5a. The PL peaks are related to the radiative recombination of photo-excited electron-hole pairs ${ }^{39}$. Compared to $\mathrm{CN}$, the $\mathrm{Bt}-\mathrm{CN}, \mathrm{OA}-\mathrm{CN}$, and $\mathrm{Bt}-\mathrm{OA}-\mathrm{CN}$ samples exhibited remarkable fluorescence-quenching behaviour (particularly Bt-OA-CN), which suggests that photogenerated electron delocalization at the $\mathrm{N}$-defect and O-replacement sites, as well as the cyano groups, lower the surface traps for charge-carrier recombination in the modified photocatalysts. The TRPL results are shown in Fig. 5b. All samples exhibit decay curves that are well fitted to the following equation ${ }^{79}$ :

$$
I_{(t)}=A_{1} \exp \left(-\frac{t}{\tau_{1}}\right)+A_{2} \exp \left(-\frac{t}{\tau_{2}}\right)+A_{3} \exp \left(-\frac{t}{\tau_{3}}\right),
$$

where $A_{1}, A_{2}$, and $A_{3}$ denote pre-exponential factors, and $\tau_{1}, \tau_{2}$, and $\tau_{3}$ are fluorescence-decay lifetimes. The average lifetime $(<\tau\rangle)$ was calculated using the following equation ${ }^{79}$ :

$$
<\tau>=\frac{A_{1} \tau_{1}^{2}+A_{2} \tau_{2}^{2}+A_{3} \tau_{3}^{2}}{A_{1} \tau_{1}+A_{2} \tau_{2}+A_{3} \tau_{3}} .
$$



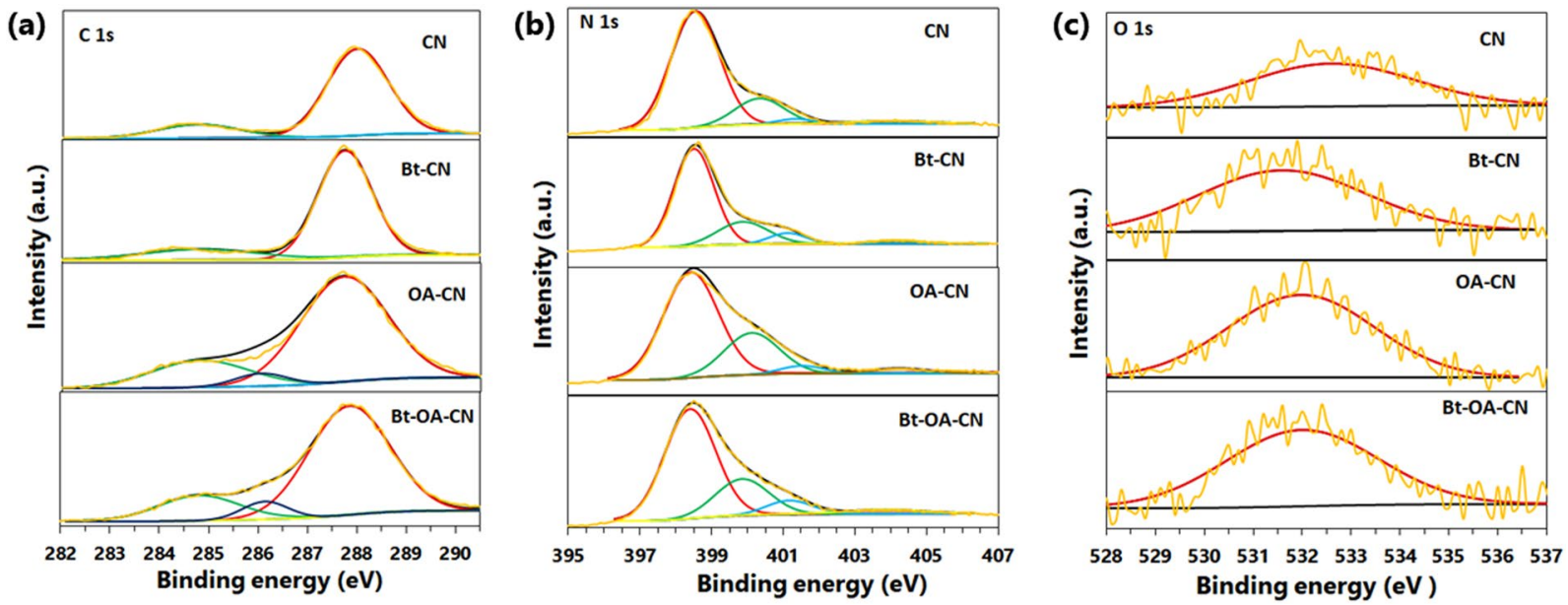

Figure 4. High resolution (a) C1s, (b) N1s, and (c) O1s XPS spectra of CN, Bt-CN, OA-CN, and Bt-OA-CN.

(a)

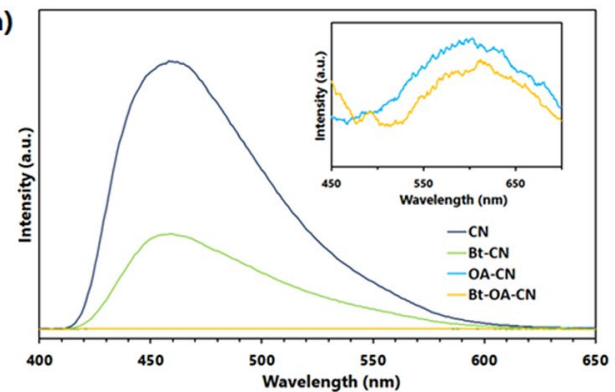

(c)

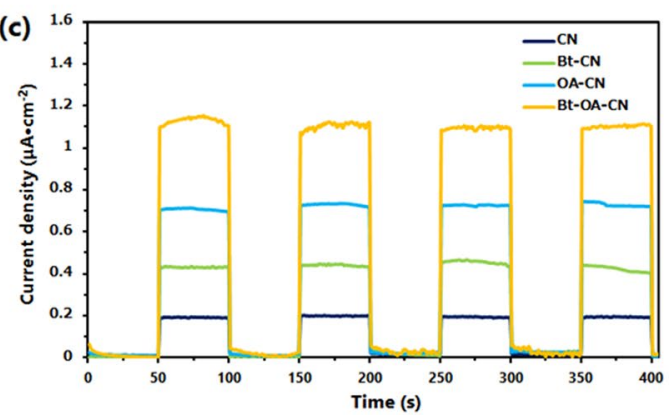

(b)

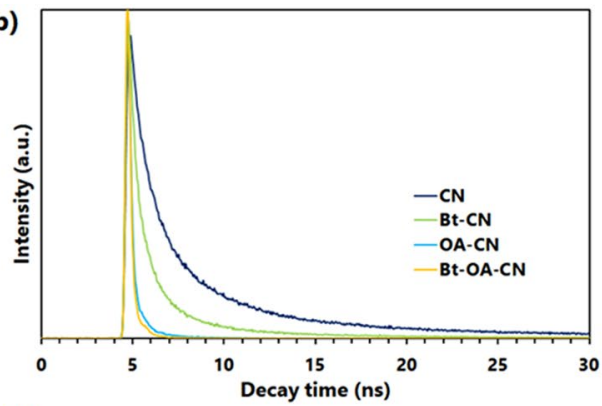

(d)

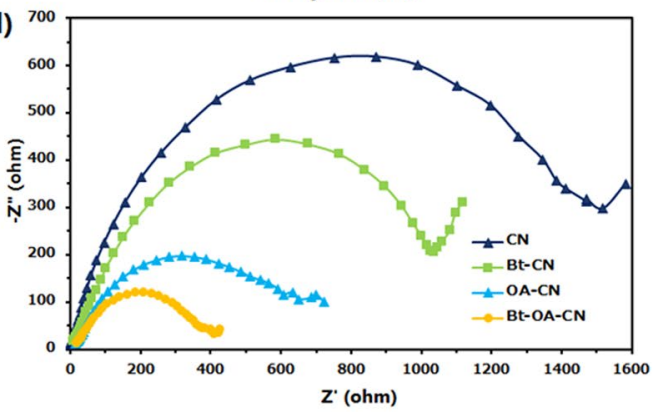

Figure 5. (a) PL spectra (inset: enlarged PL spectra of OA-CN and Bt-OA-CN), (b) TRPL spectra, (c) transient photocurrent responses, and (d) EIS Nyquist plots of $\mathrm{CN}, \mathrm{Bt}-\mathrm{CN}, \mathrm{OA}-\mathrm{CN}$, and Bt-OA-CN.

The calculated data are shown in Table S3. The average decay lifetime of the Bt-OA-CN photocatalyst was determined to be $0.208 \mathrm{~ns}$, which is 35 -fold shorter than that of $\mathrm{CN}$ ( $7.85 \mathrm{~ns}$ ). The observed suppression of the radiative recombination and shortened PL lifetime (Fig. 5a and b) are attributed to the presence of the band-tails-involved rapid recombination processes of electron-hole pairs in g- $\mathrm{C}_{3} \mathrm{~N}_{4}$ framework with the defects sites $^{47,80,81}$. The band tails act as shallow trap states of charge carriers, and an increased band tails can enhance the rapid PL processes. The dual-defects in $\mathrm{g}-\mathrm{C}_{3} \mathrm{~N}_{4}$ framework suppress the recombination of photogenerated charge carriers due to the band-to-tail charge transfer processes induced by the increased band tails. These are favorable to the photocatalytic reactions. The increased band tails resulted from $\mathrm{N}$-defects and $\mathrm{O}$-doping cause the suppression of radiative electron-hole recombination by introducing abundant shallow charge trapping states.

The (photo)electrochemical properties of $\mathrm{CN}$ and the modified $\mathrm{CNs}$ were measured by electrochemical impedance spectroscopy (EIS) and their transient photocurrent responses. As shown in Fig. 5c, the modified CNs, particularly Bt-OA-CN, display significantly improved photocurrents with respect to CN, implying enhanced charge separation. The EIS Nyquist plots of the modified CNs, particularly Bt-OA-CN, exhibit smaller radii compared to that of $\mathrm{CN}$ (Fig. 5d), indicating that structural modification results in improved resistance for charge transfer, leading to more efficient separation, transfer, and migration of charge carriers. These results are consistent with those from PL and TRPL studies. Therefore, dual defects, such as N-deficiencies and O-dopants, can promote charge transfer in the $g-\mathrm{C}_{3} \mathrm{~N}_{4}$ framework, which enhances the photocatalytic activity. 

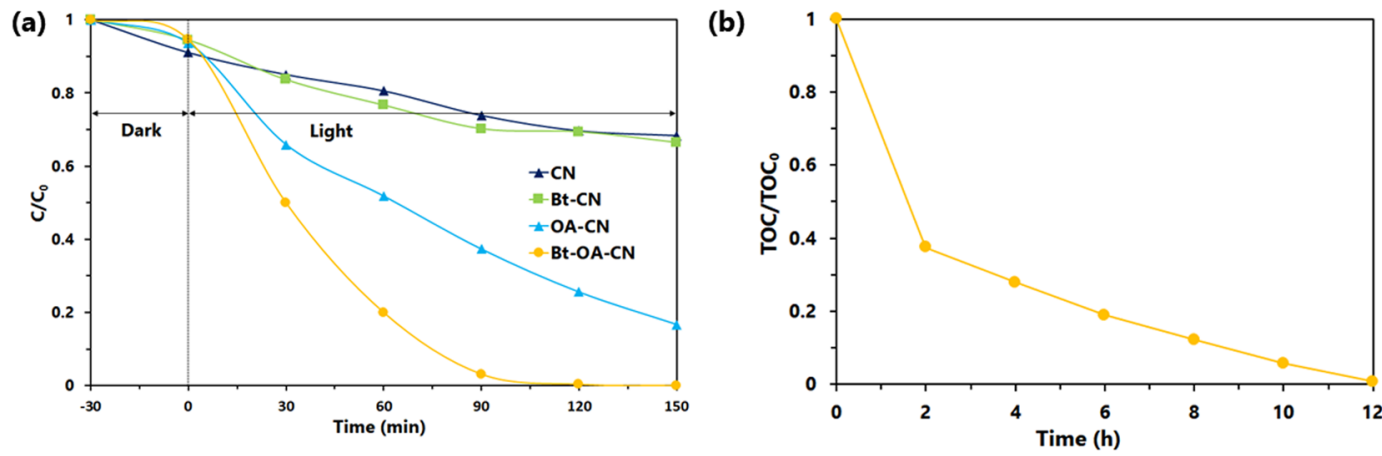

Figure 6. (a) Photocatalytic activities of $\mathrm{CN}, \mathrm{Bt}-\mathrm{CN}, \mathrm{OA}-\mathrm{CN}$, and Bt-OA-CN toward the degradation of BPA, and $(\mathbf{b})$ relative TOC content from BPA over Bt-OA-CN under visible light irradiation as a function of time.

Photocatalytic activities of the photocatalysts. To evaluate the photocatalytic activities of $\mathrm{CN}$ and the modified CNs, BPA was degraded under visible light irradiation in activity experiments. The effects of the amounts of $\mathrm{KOH}$ and oxalic acid during thermal polymerization on photocatalytic activity were investigated, the results of which are shown in Fig. S4, which clearly reveals that the optimum conditions for the thermal polymerization of $\mathrm{g}-\mathrm{C}_{3} \mathrm{~N}_{4}$ include the addition of $0.1 \mathrm{~g}$ of $\mathrm{KOH}$ and $5.0 \mathrm{~g}$ of oxalic acid to $15 \mathrm{~g}$ of the urea precursor. Figure 6a shows the photocatalytic degradation of BPA as a function of irradiation time over each photocatalyst. As shown in Fig. 6a, each modified g- $\mathrm{C}_{3} \mathrm{~N}_{4}$ photocatalyst exhibits higher photocatalytic activity than that of $\mathrm{CN}$. CN shows the lowest photocatalytic activity, with $32 \%$ of the BPA degraded after 150 min of irradiation with visible light. Among the modified g- $\mathrm{C}_{3} \mathrm{~N}_{4}$ photocatalysts, Bt-OA-CN exhibited the highest photocatalytic activity for the degradation of BPA; BPA was completely degraded within 150 min over Bt-OA-CN. The pseudo-first-order reaction rate constant for the degradation of BPA under visible light over Bt-OA-CN was $0.025 \mathrm{~min}^{-1}$, which is 11.4 times greater than that of $\mathrm{CN}\left(0.0022 \mathrm{~min}^{-1}\right)$.

The wavelength dependence of the photocatalytic activity for the degradation of BPA over Bt-OA-CN was examined using different wavelength band-pass filters (Fig. S5). Degradation efficiency was observed to decrease with increasing wavelength, although BPA degraded over $6 \mathrm{~h}$ using Bt-OA-CN even when irradiated with $600-\mathrm{nm}$ light; on the other hand, BPA was not degraded by CN when irradiated at $600 \mathrm{~nm}$. These results suggest that we successfully expanded the incident wavelength range of $\mathrm{CN}$ for the degradation of BPA to more useful values through the formation of Bt-OA-CN. BPA solution-mineralization progress over the Bt-OA-CN photocatalyst was monitored by analysing the total organic carbon content (TOC), which was observed to rapidly decrease with increasing irradiation time; the remaining TOC content of the BPA solution was not detected after $12 \mathrm{~h}$ of irradiation with visible light (Fig. 6b), reflecting the fact that BPA was completely mineralized into $\mathrm{CO}_{2}$ and $\mathrm{H}_{2} \mathrm{O}$. The TOC results indicate that the use of Bt-OA-CN is effective for not only for removal, but also for the mineralization of BPA in water samples.

In order to examine the photocatalytic stability of the Bt-OA-CN sample under visible light, the same powder sample was used five times after washing with water prior to each run. As seen in Fig. S6, the photocatalytic activity gradually decreased to $83 \%$ after five-cycles of use, which is ascribable to the adsorption and accumulation of insoluble intermediate compounds from the degradation of BPA onto the surface of the Bt-OA-CN photocatalyst and/or the loss of photocatalytic particles during stability testing. However, the observed decrease in degradation efficiency is considered to be within tolerance levels; therefore, we conclude that the Bt-OA-CN photocatalyst is highly stable under visible-light irradiation and is expected to be effective for practical applications.

Photocatalysis mechanism. To investigate the photocatalysis mechanism associated with the Bt-OA-CN catalyst, trapping experiments were conducted in order to determine the predominant photogenerated active species during the degradation of BPA. To capture $\bullet \mathrm{OH}, \mathrm{h}^{+}$, and $\mathrm{O}_{2}{ }^{--}, t$-butyl alcohol (TBA), ammonium oxalate $(\mathrm{AO})$, and benzoquinone $(\mathrm{BQ})$, which act as scavengers, were added to the photocatalysis mixture, respectively. As shown in Fig. S7, the degradation of BPA was only weakly inhibited by the addition of TBA, which suggests that $\bullet \mathrm{OH}$ is not main active species in this system. On the other hand, the photocatalytic degradation of BPA was clearly lower in the presence of $\mathrm{AO}$ and $\mathrm{BQ}$. It is therefore very likely that $\mathrm{h}^{+}$and $\mathrm{O}_{2}{ }^{--}$are the dominant reactive species involved in the photocatalytic degradation of BPA under visible-light irradiation catalysed by Bt-OA-CN.

The band structure also provides important photocatalysis-mechanism clues. Figure $3 \mathrm{~b}$ reveals that the $\mathrm{CB}$ potential for Bt-OA-CN is $-0.18 \mathrm{eV}$, which is higher than the $\mathrm{O}_{2} / \mathrm{O}_{2}{ }^{-}$redox potential $(-0.046 \mathrm{eV} \text { vs. NHE })^{66}$, whereas the $\mathrm{VB}$ potential $(+1.97 \mathrm{eV})$ is less positive than that for $\bullet \mathrm{OH} / \mathrm{H}_{2} \mathrm{O}(+2.27 \mathrm{eV}$ vs. $\mathrm{NHE})$ and $\bullet \mathrm{OH} / \mathrm{OH}^{-}$ $(+1.99 \mathrm{eV} \text { vs. NHE })^{66}$. Therefore, the electrons on the Bt-OA-CN surface are able to react with $\mathrm{O}_{2}$ to generate $\mathrm{O}_{2}{ }^{--}$, while the holes in the $\mathrm{VB}$ are unable to oxidize adsorbed $\mathrm{OH}^{-}$and $\mathrm{H}_{2} \mathrm{O}$ on the catalyst to form $\bullet \mathrm{OH}$ directly in the Bt-OA-CN photocatalysis system, which is not inconsistent with the scavenging results described above.

Based on the above discussion, we propose the enhanced photocatalytic mechanism of the Bt-OA-CN catalyst toward the degradation of BPA shown in Fig. 7. The introduction of $\mathrm{O}$ atoms into the heptazine units red-shifts their light-absorption range to over $700 \mathrm{~nm}$, inhibits the recombination of hole-electron pairs, and modifies the positions of the $\mathrm{VB}$ and $\mathrm{CB}$; the $\mathrm{VB}$ edge moves downwards from $1.85 \mathrm{eV}$ to $1.97 \mathrm{eV}$, which contributes to the increased oxidizing power of this material for the oxidative degradation of BPA. The N-deficiencies in the 


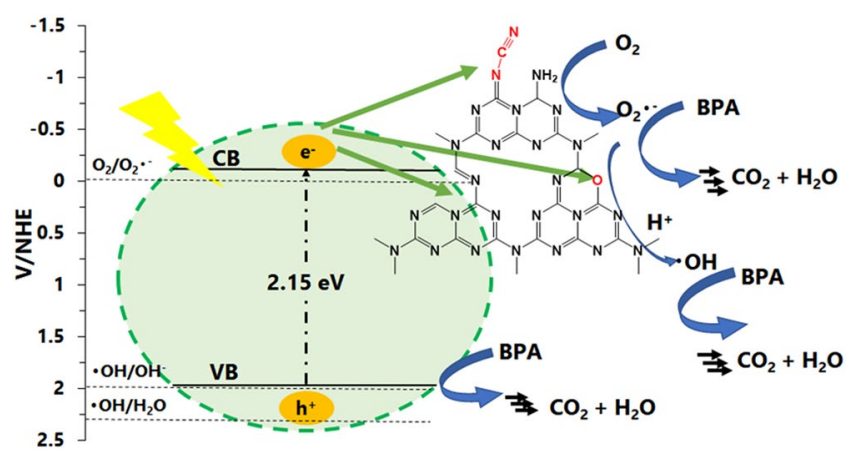

Figure 7. Proposed mechanism for the photocatalytic behaviour of Bt-OA-CN under visible light irradiation.

g- $\mathrm{C}_{3} \mathrm{~N}_{4}$ framework also facilitate enhanced light absorption and efficient charge separation. In addition, strong electron-withdrawing groups (i.e., the cyano groups) were introduced into g- $\mathrm{C}_{3} \mathrm{~N}_{4}$; hence, photogenerated electrons in the CB gather on the cyano groups, after which they react with $\mathrm{O}_{2}$ to produce $\mathrm{O}_{2}{ }^{--}$at these sites, leading to efficient separation and charge transfer at the surface. Huan et al. reported that $\mathrm{N}$-defects at secondary nitrogen sites and $\mathrm{C}-\mathrm{O}-\mathrm{C}$ species act as the active sites for the photocatalytic reaction ${ }^{82}$. However, $-\mathrm{OH}$ species caused negative effects, even though there were numerous active sites. Therefore, Bt-OA-CN exhibits excellent photocatalytic activity because there are no-OH species in its framework. The developed Bt-OA-CN preparation method introduces only favourable functionalities that positively affect photocatalytic activity. On the other hand, the remaining $\mathrm{h}^{+} \mathrm{s}$ in the $\mathrm{VB}$ of Bt-OA-CN engender this material with a much higher oxidizing ability compared to $\mathrm{CN}$, which may directly degrade BPA. Thus, these favourable dual structural modifications exhibit synergism that accelerates the photocatalytic activity of g- $\mathrm{C}_{3} \mathrm{~N}_{4}$.

In summary, dual modifications, namely $\mathrm{N}$-deficiencies and $\mathrm{O}$-dopants, were successfully introduced into the $\mathrm{g}-\mathrm{C}_{3} \mathrm{~N}_{4}$ framework by the addition of $\mathrm{KOH}$ and oxalic acid during the synthesis of $\mathrm{g}-\mathrm{C}_{3} \mathrm{~N}_{4}$ from urea. The obtained Bt-OA-CN photocatalyst exhibits a modulated energy band structure, separated photo-induced charge carriers, and an expanded light-absorption edge (over $700 \mathrm{~nm}$ ), which are ascribable to the $\mathrm{N}$ vacancies and $\mathrm{O}$ dopants. In addition to this dual modification, we confirmed the introduction of cyano groups in the Bt-OA-CN photocatalyst, which serve as strong electron-withdrawing groups that efficiently separate and transfer charge carriers to the surface of the photocatalyst. Bt-OA-CN completely decomposed BPA within 150 min with a high pseudo-first-order reaction rate constant of $0.0225 \mathrm{~min}^{-1}$, which is 11.4 -times greater than that of $\mathrm{CN}$. The superior photocatalytic activity is ascribable to synergism between these favourable dual structural modifications. PL, TRPL, and (photo)electrochemical techniques reveal the induction of the efficient separation and transfer of charge carriers, while quenching experiments show that both $\mathrm{h}^{+}$and $\mathrm{O}_{2}{ }^{--}$are the predominant oxidizing species in the Bt-OA-CN photocatalyst system. This research provides a simple and easy method for creating structural defects in $\mathrm{g}-\mathrm{C}_{3} \mathrm{~N}_{4}$, and introduces Bt-OA-CN as a promising highly efficient visible-light-responsive photocatalyst for use in environmental-remediation applications.

\section{Methods}

Photocatalyst preparation. All reagents used in these experiments were of analytical grade and were used without further purification. Urea, $\mathrm{KOH}$, and oxalic acid were obtained from FUJIFILM Wako Pure Chemicals. $\mathrm{CN}$ was prepared by directly heating urea to $550^{\circ} \mathrm{C}$ in a muffle furnace for $5 \mathrm{~h}$ in a covered alumina crucible at a rate of $3^{\circ} \mathrm{C} / \mathrm{min}$. Bt-OA-CN was synthesized as follows: $15 \mathrm{~g}$ of urea was dissolved in $30 \mathrm{~mL}$ of an aqueous solution of $\mathrm{KOH}(0.1 \mathrm{~g})$. After stirring for $3 \mathrm{~h}$, the resulting solution was evaporated to dryness at $80^{\circ} \mathrm{C}$ using a hot stirrer. The obtained solid was then ground with $5 \mathrm{~g}$ of oxalic acid in a mortar. The resultant powder was calcined at $550^{\circ} \mathrm{C}$ in a muffle furnace for $5 \mathrm{~h}$ at a rate of $3^{\circ} \mathrm{C} / \mathrm{min}$. Bt-CN and OA-CN were prepared using the same procedure without the addition of oxalic acid and $\mathrm{KOH}$, respectively.

Characterization. XRD patterns were recorded on a RIGAKU Ultima IV diffractometer equipped with a Cu $\mathrm{K} \alpha$ radiation source. The morphologies of the samples were examined with a Hitachi S- 4000 SEM and a JEOL JEM-1011 TEM. FTIR spectra of the samples were acquired on a SPECTRUM 100 FTIR spectrometer (Perkin Elmer) equipped with an ATR assembly. UV-vis DRS was performed with a JASCO V-750 UV-vis spectrometer equipped with an integrating sphere attachment. XPS was performed using a PHI Quantera SXM photoelectron spectrometer with $\mathrm{Al} \mathrm{K \alpha}$ radiation. $\mathrm{N}_{2}$ adsorption-desorption isotherms were acquired using a BELSORP-miniII (MicrotracBEL) apparatus. The samples were degassed at $180^{\circ} \mathrm{C}$ for $18 \mathrm{~h}$ under vacuum prior to any experiment. Specific surface areas and pore-size distributions of the samples were calculated using the BET and BJH methods. PL spectra were acquired on a Shimadzu RF-5300PC system. TRPL experiments were performed on a Quantaurus-Tau C11367 spectrophotometer (Hamamatsu Photonics) at an excitation wavelength of $372 \mathrm{~nm}$. Photoelectrochemical experiments were carried out in a conventional three-electrode system with an electrochemical workstation (VersaSTAT 3, Princeton Applied Research). A saturated Ag/AgCl electrode and a platinum electrode were used as the reference and counter electrodes, respectively. The working electrodes were prepared by depositing the photocatalyst slurry onto ITO as the substrate. An aqueous solution of $0.5 \mathrm{~mol} / \mathrm{L} \mathrm{Na}_{2} \mathrm{SO}_{4}$ was used as the electrolyte. The working electrode was irradiated by a 300-W Xe lamp (MAX-303, Asahi Spectra) with a UV cut-off filter (L-42, HOYA). 
Evaluating photocatalytic activity. The photocatalytic activities of the synthesized catalysts were evaluated by degrading BPA under visible-light irradiation. In typical run, $30 \mathrm{mg}$ of the photocatalyst was added to $30 \mathrm{~mL}$ of BPA solution $(10 \mathrm{mg} / \mathrm{L})$ in a $50-\mathrm{mL}$ Pyrex glass reactor. The mixture solution was stirred in dark for $30 \mathrm{~min}$ to reach adsorption-desorption equilibrium, after which the sample solution was irradiated using a 300-W Xe lamp (MAX-303, Asahi Spectra) with a UV cut-off filter (L-42, HOYA) while stirring was maintained. After the desired irradiation time, the suspension was centrifuged to remove the photocatalyst and the supernatant was used to determine the concentration of residual BPA by HPLC (GL Science) using an ODS-100V column $(150 \mathrm{~mm} \times 4.6 \mathrm{~mm}$ i.d., TOSOH) and a GL-7450 UV detector (GL Science) operating at $276 \mathrm{~nm}$. A 6:4 (v/v) mixture of acetonitrile and water was used as the mobile phase at a flow rate of $1.0 \mathrm{~mL} / \mathrm{min}$. BPA-mineralization progress was confirmed by measuring the TOC, which was determined with a Shimadzu TOC analyser (TOC-V $\mathrm{V}_{\mathrm{E}}$ ). For radical trapping experiments, the scavenger for each reactive species was added to the reaction solution in a manner similar to that described for the photocatalytic experiment (above). The scavenger concentrations were: $0.1,1 \times 10^{-3}$, and $1 \times 10^{-4} \mathrm{~mol} \mathrm{~L}^{-1}$ for TBA, $\mathrm{AO}$, and $\mathrm{BQ}$, respectively.

Received: 10 April 2019; Accepted: 3 September 2019;

Published online: 16 October 2019

\section{References}

1. Wang, X. et al. A metal-free polymeric photocatalyst for hydrogen production from water under visible light. Nat. Mater. 8, 76-80 (2009).

2. Chen, X., Zhang, J., Fu, X., Antonietti, M. \& Wang, X. Fe-g- $\mathrm{C}_{3} \mathrm{~N}_{4}$-catalyzed oxidation of benzene to phenol using hydrogen peroxide and visible light. J. Am. Chem. Soc. 131, 11658-11659 (2009).

3. Wang, Y., Zhang, J., Wang, X., Antonietti, M. \& Li, H. Boron- and fluorine-containing mesoporous carbon nitride polymers: metalfree catalysts for cyclohexane oxidation. Angew. Chem. Int. Ed. 49, 3356-3359 (2010).

4. Dong, G. \& Zhang, L. Porous structure dependent photoreactivity of graphitic carbon nitride under visible light. J. Mater. Chem. 22, $1160-1166$ (2012).

5. Zhang, X. et al. Enhanced photoresponsive ultrathin graphitic-phase $\mathrm{C}_{3} \mathrm{~N}_{4}$ nanosheets for bioimaging. J. Am. Chem. Soc. 135, 18-21 (2013).

6. Ong, W.-J., Tan, L.-L., Ng, Y. H., Yong, S.-T. \& Chai, S.-P. Graphitic carbon nitride $\left(\mathrm{g}-\mathrm{C}_{3} \mathrm{~N}_{4}\right)$-based photocatalysts for artificial photosynthesis and environmental remediation: Are we a step closer to achieving sustainability? Chem. Rev. 116, 7159-7329 (2016).

7. She, X. et al. High efficiency photocatalytic water splitting using $2 \mathrm{D} \alpha-\mathrm{Fe}_{2} \mathrm{O}_{3} / g-\mathrm{C}_{3} \mathrm{~N}_{4} \mathrm{Z}$-scheme catalysts. Adv. Energy Mater. 7, 1700025, https://doi.org/10.1002/aenm.201700025 (2017).

8. Fu, J. et al. Hierarchical porous O-doped g- $\mathrm{C}_{3} \mathrm{~N}_{4}$ with enhanced photocatalytic $\mathrm{CO}_{2}$ reduction activity. Small 13, 1603938, https:// doi.org/10.1002/smll.201603938 (2017).

9. Zhang, G., Lan, Z.-A., Lin, L., Lin, S. \& Wang, X. Overall water splitting by Pt/g- $\mathrm{C}_{3} \mathrm{~N}_{4}$ photocatalysts without using sacrificial agents. Chem. Sci. 7, 3062-3066 (2016).

10. Zhang, G., Lan, Z.-A. \& Wang, X. Surface engineering of graphitic carbon nitride polymers with cocatalysts for photocatalytic overall water splitting. Chem. Sci. 8, 5261-5274 (2017).

11. Xu, H. et al. $2 \mathrm{D}$ heterostructure comprised of metallic $1 \mathrm{~T}-\mathrm{MoS}_{2} / \mathrm{Monolayer} \mathrm{O}-\mathrm{g}-\mathrm{C}_{3} \mathrm{~N}_{4}$ towards efficient photocatalytic hydrogen evolution. Appl. Catal. B 220, 379-385 (2018).

12. Xu, B. et al. Graphitic carbon nitride based nanocomposites for the photocatalysis of organic contaminants under visible irradiation: Progress, limitations and future directions. Sci. Total Environ. 633, 546-559 (2018).

13. Chu, M. et al. Synthesis of g- $\mathrm{C}_{3} \mathrm{~N}_{4}$-based photocatalysts with recyclable feature for efficient 2,4-dichlorophenol degradation and mechanism. Appl. Catal. B 243, 57-65 (2019).

14. Jiang, L. et al. Construction of an all-solid-state Z-scheme photocatalyst based on graphite carbon nitride and its enhancement to catalytic activity. Environ Sci.: Nano 5, 599-615 (2018).

15. Zeng, P., Ji, X., Su, Z. \& Zhang, S. $\mathrm{WS}_{2} /$ g- $\mathrm{C}_{3} \mathrm{~N}_{4}$ composite as an efficient heterojunction photocatalyst for biocatalyzed artificial photosynthesis. RSC Adv. 8, 20557-20567 (2018).

16. Huang, D. et al. Graphitic carbon nitride-based heterojunction photoactive nanocomposites: applications and mechanism insight. ACS Appl. Mater. Interfaces 10, 21035-21055 (2018).

17. Yin, S., Han, J., Zhou, T. \& Xu, R. Recent progress in $\mathrm{g}-\mathrm{C}_{3} \mathrm{~N}_{4}$ based low cost photocatalytic system: Activity enhancement and emerging applications. Catal. Sci. Technol. 5, 5048-5061 (2015).

18. Cao, S., Low, J., Yu, J. \& Jaroniec, M. Polymeric photocatalysts based on graphitic carbon nitride. Adv. Mater. 27, 2150-2176 (2015).

19. Zhao, Z., Sun, Y. \& Dong, F. Graphitic carbon nitride based nanocomposites: A review. Nanoscale 7, 15-37 (2015).

20. Kessler, F. K. et al. Functional carbon nitride materials-design strategies for electrochemical devices. Nat. Rev. Mater. 2, 17030, https://doi.org/10.1038/natrevmats.2017.30 (2017).

21. Niu, P., Zhang, L., Liu, G. \& Cheng, H.-M. Graphene-like carbon nitride nanosheets for improved photocatalytic activities. Adv. Funct. Mater. 22, 4763-4770 (2012).

22. Hou, Y., Wen, Z., Cui, S., Guo, X. \& Chen, J. Constructing $2 \mathrm{D}$ porous graphitic $\mathrm{C}_{3} \mathrm{~N}_{4}$ nanosheets/nitrogen-doped graphene/layered $\mathrm{MoS}_{2}$ ternary nanojunction with enhanced photoelectrochemical activity. Adv. Mater. 25, 6291-6297 (2013).

23. Mo, Z. et al. Self-assembled synthesis of defect-engineered graphitic carbon nitride nanotubes for efficient conversion of solar energy. Appl. Catal. B 225, 154-161 (2018).

24. Zhao, C. et al. Probing supramolecular assembly and charge carrier dynamics toward enhanced photocatalytic hydrogen evolution in 2D graphitic carbon nitride nanosheets. Appl. Catal. B 256, 117867 (2019).

25. Jiang, Y. et al. Self-assembled g- $\mathrm{C}_{3} \mathrm{~N}_{4}$ nanoarchitectures with boosted photocatalytic solar-to-hydrogen efficiency. Appl. Surface Sci. 487, 59-67 (2019).

26. Ran, R. J., Ma, T. Y., Gao, G., Du, X.-W. \& Qiao, S. Z. Porous P-doped graphitic carbon nitride nanosheets for synergistically enhanced visible-light photocatalytic $\mathrm{H}_{2}$ production. Energy Environ Sci. 8, 3708-3717 (2015).

27. Guo, S. et al. P-doped tubular g- $\mathrm{C}_{3} \mathrm{~N}_{4}$ with surface carbon defects: Universal synthesis and enhanced visible-light photocatalytic hydrogen production. Appl. Catal. B 218, 664-671 (2017).

28. Wang, H., Wang, B., Bian, Y. \& Dai, L. Enhancing photocatalytic activity of graphitic carbon nitride by codoping with P and C for efficient hydrogen generation. ACS Appl. Mater. Interfaces 9, 21730-21737 (2017).

29. Mitsuyama, T., Katsumata, H., Suzuki, T. \& Kaneco, S. Enhanced photocatalytic activity of phosphorus-doped graphitic carbon nitride under visible light irradiation. ECS Trans. 75, 47-56 (2017).

30. Feng, J. et al. Coupling $\mathrm{P}$ nanostructures with P-doped $g-\mathrm{C}_{3} \mathrm{~N}_{4}$ as efficient visible light photocatalysts for $\mathrm{H}_{2}$ evolution and RhB degradation. ACS Sustainable Chem. Eng. 6, 6342-6349 (2018).

31. Liu, Q. et al. Unveiling the origin of boosted photocatalytic hydrogen evolution in simultaneously (S, P, O)-Codoped and exfoliated ultrathin g- $\mathrm{C}_{3} \mathrm{~N}_{4}$ nanosheets. Appl. Catal. B 248, 84-94 (2019). 
32. Fang, S. et al. Effect of carbon-dots modification on the structure and photocatalytic activity of g- $\mathrm{C}_{3} \mathrm{~N}_{4}$. Appl. Catal. B: Environ. 185, 225-232 (2016).

33. Nakai, Y., Katsumata, H., Suzuki, T. \& Kaneco, S. Highly efficient visible-light-driven photocatalytic $\mathrm{H}_{2}$ production using carbon particle/g- $\mathrm{C}_{3} \mathrm{~N}_{4}$ photocatalysts with an electron donor. ECS Trans. 75, 75-84 (2017).

34. Safaei, J. et al. Graphitic carbon nitride $\left(\mathrm{g}-\mathrm{C}_{3} \mathrm{~N}_{4}\right)$ electrodes for energy conversion and storage: A review on photoelectrochemical water splitting, solar cells and supercapacitors. J. Mater. Chem. A 6, 22346-22380 (2018).

35. Liu, Y. et al. In situ construction of fibrous AgNPs/g- $\mathrm{C}_{3} \mathrm{~N}_{4}$ aerogel toward light-driven $\mathrm{CO}_{\mathrm{x}}$-free methanol dehydrogenation at room temperature. Chem. Eng. J. 334, 2401-2407 (2018).

36. Tang, H. et al. Oxamide-modified g- $\mathrm{C}_{3} \mathrm{~N}_{4}$ nanostructures: Tailoring surface topography for high-performance visible light photocatalysis. Chem. Eng. J. 374, 1064-1075 (2019).

37. Teng, Z. et al. Edge-functionalized g- $\mathrm{C}_{3} \mathrm{~N}_{4}$ nanosheets as a highly efficient metal-free photocatalyst for safe drinking water. Chem $\mathbf{5}$, 664-680 (2019)

38. Wu, X., Gao, D., Yu, H. \& Yu, J. High-yield lactic acid-mediated route for a g- $\mathrm{C}_{3} \mathrm{~N}_{4}$ nanosheet photocatalyst with enhanced $\mathrm{H}_{2}$ evolution performance. Nanoscale 11, 9608-9616 (2019).

39. Katsumata, H., Sakai, T., Suzuki, T. \& Kaneco, S. Highly efficient photocatalytic activity of $g-\mathrm{C}_{3} \mathrm{~N}_{4} / \mathrm{Ag}_{3} \mathrm{PO}_{4}$ hybrid photocatalysts through Z-scheme photocatalytic mechanism under visible light. Ind. Eng. Chem. Res. 53, 8018-8025 (2014).

40. Katsumata, H., Tachi, Y., Suzuki, T. \& Kaneco, S. Z-scheme photocatalytic hydrogen production over $\mathrm{WO}_{3} / \mathrm{g}-\mathrm{C}_{3} \mathrm{~N}_{4}$ composite photocatalysts. RSC Adv. 4, 21405-21409 (2014).

41. Di, T., Zhu, B., Cheng, B., Yu, J. \& Xu, J. A direct Z-scheme g- $\mathrm{C}_{3} \mathrm{~N}_{4} / \mathrm{SnS}_{2}$ photocatalyst with superior visible-light $\mathrm{CO}_{2}$ reduction performance. J. Catal. 352, 532-541 (2017).

42. Tian, L., Yang, X., Liu, Q., Qu, F. \& Tang, H. Anchoring metal-organic framework nanoparticles on graphitic carbon nitrides for solar-driven photocatalytic hydrogen evolution. Appl. Surface Sci. 455, 403-409 (2018).

43. Liu, W., Shen, J., Liu, Q., Yang, X. \& Tang, H. Porous MoP network structure as co-catalyst for $\mathrm{H}_{2}$ evolution over g- $\mathrm{C}_{3} \mathrm{~N}_{4}$ nanosheets. Appl. Surface Sci. 462, 822-830 (2018).

44. Yang, X. et al. Interfacial optimization of g- $\mathrm{C}_{3} \mathrm{~N}_{4}$-based Z-scheme heterojunction toward synergistic enhancement of solar-driven photocatalytic oxygen evolution. Appl. Catal. B: Environ. 244, 240-249 (2019).

45. Zhao, X. et al. g- $\mathrm{C}_{3} \mathrm{~N}_{4}$ photoanode for photoelectrocatalytic synergistic pollutant degradation and hydrogen evolution. Appl. Surface Sci. 467/468, 658-665 (2019).

46. Niu, P., Yin, L.-C., Yang, Y.-Q., Liu, G. \& Cheng, H.-M. Increasing the visible light absorption of graphitic carbon nitride (melon) photocatalysts by homogeneous self-modification with nitrogen vacancies. Adv. Mater. 26, 8046-8052 (2014).

47. Niu, P., Liu, G. \& Cheng, H.-M. Nitrogen vacancy-promoted photocatalytic activity of graphitic carbon nitride. J. Phys. Chem. C 116, 11013-11018 (2012).

48. Lin, Z. \& Wang, X. Nanostructure engineering and doping of conjugated carbon nitride semiconductors for hydrogen photosynthesis. Angew. Chem. Int. Ed. 52, 1735-1738 (2013).

49. Zhang, Y., Gao, J. \& Chen, Z. A solid-state chemical reduction approach to synthesize graphitic carbon nitride with tunable nitrogen defects for efficient visible-light photocatalytic hydrogen evolution. J. Colloid Interface Sci. 535, 331-340 (2019).

50. Shi, H. et al. Defects promote ultrafast charge separation in graphitic carbon nitride for enhanced visible-light-driven $\mathrm{CO}_{2}$ reduction activity. Chem. Eur. J. 25, 5028-5035 (2019).

51. Hong, Z., Shen, B., Chen, Y., Lin, B. \& Gao, B. Enhancement of photocatalytic $\mathrm{H}_{2}$ evolution over nitrogen-deficient graphitic carbon nitride. J. Mater. Chem. A 1, 11754-11761 (2013).

52. Tu, W. et al. Investigating the role of tunable nitrogen vacancies in graphitic carbon nitride nanosheets for efficient visible-lightdriven $\mathrm{H}_{2}$ evolution and $\mathrm{CO}_{2}$ reduction. ACS Sustainable Chem. Eng. 5, 7260-7268 (2017).

53. Niu, P., Qiao, M., Li, Y., Huang, L. \& Zhai, T. Distinctive defects engineering in graphitic carbon nitride for greatlyextended visible light photocatalytic hydrogen evolution. Nano Energy 44, 73-81 (2018).

54. Yu, H. et al. Alkali-assisted synthesis of nitrogen deficient graphitic carbon nitride with tunable band structures for efficient visiblelight-driven hydrogen evolution. Adv. Mater. 29, 1605148, https://doi.org/10.1002/adma.201605148 (2017).

55. Zhou, L. et al. Recent advances in non-metal modification of graphitic carbon nitride for photocatalysis: A historic review. Catal. Sci. Technol. 6, 7002-7023 (2016).

56. Ming, L., Yue, H., Xu, L. \& Chen, F. Hydrothermal synthesis of oxidized $\mathrm{g}_{-} \mathrm{C}_{3} \mathrm{~N}_{4}$ and its regulation of photocatalytic activity. J. Mater. Chem. A 2, 19145-19149 (2014).

57. Huang, Z.-F. et al. Carbon nitride with simultaneous porous network and O-doping for efficient solar-energy-driven hydrogen evolution. Nano Energy 12, 646-656 (2015).

58. Yang, L. et al. A surface modification resultant thermally oxidized porous g- $\mathrm{C}_{3} \mathrm{~N}_{4}$ with enhanced photocatalytic hydrogen production. Appl. Catal. B 204, 335-345 (2017).

59. $\mathrm{Li}$, J. et al. A facile approach to synthesize novel oxygen-doped $\mathrm{g}-\mathrm{C}_{3} \mathrm{~N}_{4}$ with superior visible-light photoreactivity. Chem. Commun. 48, 12017-12019 (2012).

60. Dong, G., Ai, Z. \& Zhang, L. Efficient anoxic pollutant removal with oxygen functionalized graphitic carbon nitride under visible light. RSC Adv. 4, 5553-5560 (2014).

61. Liu, S. et al. Oxygen functional groups in graphitic carbon nitride for enhanced photocatalysis. J. Colloid Interface Sci. 468, 176-182 (2016).

62. She, X. et al. Oxygenated monolayer carbon nitride for excellent photocatalytic hydrogen evolution and external quantum efficiency. Nano Energy 27, 138-146 (2016).

63. Chao, W. et al. Hydrothermally induced oxygen doping of graphitic carbon nitride with a highly ordered architecture and enhanced photocatalytic activity. ChemSusChem 11, 700-708 (2018).

64. Zhang, J.-W. et al. Oxygen-doped nanoporous carbon nitride via water-based homogeneous supramolecular assembly for photocatalytic hydrogen evolution. Appl. Catal. B 221, 9-16 (2018).

65. Wei, F. et al. Oxygen self-doped g- $\mathrm{C}_{3} \mathrm{~N}_{4}$ with tunable electronic band structure for unprecedentedly enhanced photocatalytic performance. Nanoscale 10, 4515-4522 (2018).

66. Qiu, P. et al. One step synthesis of oxygen doped porous graphitic carbon nitridewith remarkable improvement of photo-oxidation activity: Role of oxygen on visible light photocatalytic activity. Appl. Catal. B 206, 319-327 (2017).

67. Xu, G. et al. Double defects modified carbon nitride nanosheets with enhanced photocatalytic hydrogen evolution. Phys. Chem. Chem. Phys. 20, 17471-17476 (2018).

68. Jiang, Y. et al. Enhancement of photocatalytic hydrogen evolution activity of porous oxygen doped $g-C_{3} \mathrm{~N}_{4}$ with nitrogen defects induced by changing electron transition. Appl. Catal. B 240, 30-38 (2019).

69. Thomas, A. et al. Graphitic carbon nitride materials: Variation of structure and morphology and their use as metal-free catalysts. J. Mater. Chem. 18, 4893-4908 (2008).

70. Ho, W. et al. Copolymerization with 2,4,6-triaminopyrimidine for the rolling-up the layer structure, tunable electronic properties, and photocatalysis of g- $\mathrm{C}_{3} \mathrm{~N}_{4}$. ACS Appl. Mater. Interfaces 7, 5497-5505 (2015).

71. Liu, L. et al. Synthesis and characterization of microporous carbon nitride. Microporous Mesoporous Mater. 110, 216-222 (2008).

72. Yan, S. C., Li, Z. S. \& Zou, Z. G. Photodegradation performance of $\mathrm{g}-\mathrm{C}_{3} \mathrm{~N}_{4}$ fabricated by directly heating melamine. Langmuir 25, 10397-10401 (2009). 
73. He, F. et al. The sulfur-bubble template-mediated synthesis of uniform porous $\mathrm{g}_{-} \mathrm{C}_{3} \mathrm{~N}_{4}$ with superior photocatalytic performance. Chem. Commun. 51, 425-427 (2015).

74. Zeng, Y. et al. Scalable one-step production of porous oxygen-doped g- $\mathrm{C}_{3} \mathrm{~N}_{4}$ nanorods with effective electron separation for excellent visible-light photocatalytic activity. Appl. Catal. B 224, 1-9 (2018).

75. Dong, F. et al. Efficient synthesis of polymeric $\mathrm{g}-\mathrm{C}_{3} \mathrm{~N}_{4}$ layered materials as novel efficient visible light driven photocatalysts. J. Mater. Chem. 21, 15171-15174 (2011).

76. Oh, J. et al. Oxidized carbon nitrides: water-dispersible, atomically thin carbon nitride-based nanodots and their performances as bioimaging probes. Chem. Eur. J. 21, 6241-6246 (2015).

77. Gao, H. et al. Towards efficient solar hydrogen production by intercalated carbon nitride photocatalyst. Phys. Chem. Chem. Phys. 15, 18077-18084 (2013).

78. Liu, C., Huang, H., Cui, W., Dong, F. \& Zhang, Y. Band structure engineering and efficient charge transport in oxygen substituted g- $\mathrm{C}_{3} \mathrm{~N}_{4}$ for superior photocatalytic hydrogen evolution. Appl. Catal. B 230, 115-124 (2018).

79. Xia, P., Liu, M., Cheng, B., Yu, J. \& Zhang, L. Dopamine modified $g-\mathrm{C}_{3} \mathrm{~N}_{4}$ and its enhanced visible-light photocatalytic $\mathrm{H}_{2}$-production activity. ACS Sustainable Chem. Eng. 6, 8945-8953 (2018).

80. Kang, Y. et al. Selective breaking of hydrogen bonds of layered carbon nitride for visible light photocatalysis. Adv. Mater. 28, 6471-6477 (2016).

81. Shaheer, A. R. M., Karthik, P., Karthik, G., Shankar, M. V. \& Neppolian, B. Dual role of a g- $\mathrm{C}_{3} \mathrm{~N}_{4} /$ carbon intra-Schottky junction in charge carrier generation and separation for efficient solar $\mathrm{H}_{2}$ production. Catal. Sci. Technol. 9, 3493-3503 (2019).

82. Huang et al. Revealing active-site structure of porous nitrogen-defected carbon nitride for highly effective photocatalytic hydrogen evolution. Chem. Eng. J. 373, 687-699 (2019).

\section{Acknowledgements}

This work was partly supported by a Grant-in-Aid for Scientific Research (B) No. 18H02013 from the Ministry of Education, Culture, Sports, Science, and Technology of Japan.

\section{Author contributions}

H.K. supervised the project and wrote the manuscript. H.K., F.H. and Y.K. designed and carried out all experiments. I.T., M.F. and S.K. helped to analyse the experimental results. All authors reviewed and commented on the manuscript.

\section{Competing interests}

The authors declare no competing interests.

\section{Additional information}

Supplementary information is available for this paper at https://doi.org/10.1038/s41598-019-49949-6.

Correspondence and requests for materials should be addressed to H.K.

Reprints and permissions information is available at www.nature.com/reprints.

Publisher's note Springer Nature remains neutral with regard to jurisdictional claims in published maps and institutional affiliations.

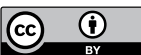

Open Access This article is licensed under a Creative Commons Attribution 4.0 International License, which permits use, sharing, adaptation, distribution and reproduction in any medium or format, as long as you give appropriate credit to the original author(s) and the source, provide a link to the Creative Commons license, and indicate if changes were made. The images or other third party material in this article are included in the article's Creative Commons license, unless indicated otherwise in a credit line to the material. If material is not included in the article's Creative Commons license and your intended use is not permitted by statutory regulation or exceeds the permitted use, you will need to obtain permission directly from the copyright holder. To view a copy of this license, visit http://creativecommons.org/licenses/by/4.0/.

(C) The Author(s) 2019 